American Journal of Infectious Diseases 7 (2): 51-54, 2011

ISSN 1553-6203

(C) 2011 Science Publications

\title{
Healthcare Associated Infections in Intensive Care Units HIV Positive Patients
}

\author{
${ }^{1}$ Lisandra Serra Damasceno, ${ }^{1}$ Evelyne Santana Girao, \\ ${ }^{2}$ Rafael Fonseca de Queiroz, ${ }^{2}$ Renato Labanca Delgado Perdigao, \\ ${ }^{3}$ Alessandra Serra Damasceno and ${ }^{1,2}$ Lara Gurgel Fernandes Tavora \\ ${ }^{1}$ St. Joseph Hospital of Infectious Diseases, \\ ${ }^{2}$ University of Fortaleza, School of Medicine, \\ ${ }^{3}$ State University of Ceara, Nursing School, \\ Fortaleza, Ceara, Brazil
}

\begin{abstract}
Problem statement: Healthcare Associated Infections (HAI) are frequent and important complications, most commonly affecting hospitalized patients in intensive care units. Hospital average length of stay is usually 5-10 days higher in these patients. In HIV positive/Aids patients HAI vary from 8,7 and $15 \%$ in prevalence. The aims of this study was to compare HAI data from HIV positive (HIV+) and HIV negative (HIV-) patients admitted to the adult Intensive Care Unit (ICU) of an Infectious Disease reference hospital located in the state of Ceara, Northeast Brazil. Approach: This was a retrospective study of all patients admitted to the Hospital Sao Jose ICU, from January 2006 to December 2007, which were diagnosed with a HAI. Results: During the study period, 144 cases of HAI were diagnosed in 106 patients. Sixty were HIV- and $46 \mathrm{HIV}+$. Eighty nine (62\%) HAI occurred in the HIV-group. The use of invasive devices, such as mechanical ventilation, central-line catheter and vesicle catheter, was identified in 114 HAI. Pneumonia was the most prevalent HAI (83/144$80 \%$ ), almost all of them related to mechanical ventilation (81/83-96\%). Density of incidence of ventilator-associated pneumonia was higher in HIV+ (HIV- : 19.9 Vs. HIV+: 24.0-p = 0.38), while the density of incidence of catheter associated urinary tract infection was higher in HIV- (HIV-: 4.5 vs. HIV+: $1.6-\mathrm{p}=0.09)$, although without statistical significance. Conclusion/Recommendation: HAI were similar in both groups. Therefore our data suggest that, HAI prevention precautions should be intensively used in all patients, especially in ICU ones, in order to minimize HAI risks and serious consequences.
\end{abstract}

Key words: Healthcare Associated Infections (HAI), Intensive Care Units (ICU), nosocomial infection, antibiotic prophylaxis, invasive device, Urinary Tract Infections (UTI), Blood Stream Infection (BSI)

\section{INTRODUCTION}

Healthcare Associated Infections (HAI) are frequent and important complications, most commonly affecting hospitalized patients. Hospital average length of stay is usually 5-10 days higher in these patients (Rosenthal et al., 2010; Kubler, 2011).

In Brazil, approximately 5-15\% of hospitalized patients are diagnosed with a nosocomial infection (Machado et al., 2001). Patients in Intensive Care Units (ICU) are at 5-10 higher risk of being affected by a nosocomial infection (Trilla, 1994). Data from the Brazilian Surveillance and Control of Pathogens of Epidemiological Importance (SCOPE) study showed that $49 \%$ of the nosocomial Blood Stream infections (BSI) occurred in ICU patients (Marra et al., 2011).

In HIV positive/Aids patients HAI vary from 8,7 and $15 \%$ in prevalence. Aids related immunosuppressant, prolonged hospital stay, use of invasive device and routine administration of antibiotic prophylaxis for opportunistic infections probably increase these patients' risk for presenting with HAI (Goetz et al., 1994; Frank et al., 1997; Stroud et al., 1997; Petrosillo et al., 1999).

Considering all settings, Urinary Tract Infections (UTI) is the most prevalent HAI. In the ICU setting, however, Ventilator-Associated Pneumonia (VAP) and BSI are the first and second more prevalent infections

Corresponding Author: Lara Gurgel Fernandes Tavora, St. Joseph Hospital of Infectious Diseases, University of Fortaleza,

315 Nestor Barbosa St., Parquelândia, Fortaleza, Ceara, Brazil 
respectively (Wenzel, 1995; Pittet and Wenzel, 1995). In HIV/Aids patients, catheter related BSI are increasing in frequency and correspond to $24-44 \%$ of all the HAI in this group (Goetz et al., 1994; Frank et al., 1997; Petrosillo et al., 1999; Padoveze et al., 2002; Petrosillo et al., 2003).

The presenting study was conducted to compare HAI data from HIV positive (HIV+) and HIV negative (HIV-) patients admitted to the adult ICU of an Infectious Disease reference hospital located in the state of Ceara, Northeast Brazil.

\section{MATERIALS AND METHODS}

This is a transversal, retrospective study. All patients admitted to St. Joseph Hospital ICU, from January 2006 to December 2007, which were diagnosed with a HAI, were included.

St Joseph Hospital is a public entity, located in the city of Fortaleza and is reference for infectious disease treatment in the state of Ceara. It is a 118 bed hospital with 7 of them in the ICU.

Data was collected from the Infection control team registers and from patients' charts. For diagnosing HAI we used the National Nosocomial Infections Surveillance System/Centers for Disease Control (NNISS/CDC) definition criteria.

The following variables, regarding the patients' history, were collected from the infection control team registers: gender, age and dates of admission, discharge and first HAI, number of HAI, use of invasive devices, infection site, HIV serology and clinical outcome. Data from the ICU were also collected: patient-days, central line-days, urinary catheter-days, ventilator-days.

The following variables were collected from patients' charts: leukocyte count, neutrophil percentage, APACHE II score (Acute Physiology and Chronic Health Evaluation II). When the patient was HIV+, CD4 count was also collected and the patient was classified using the CDC HIV infection staging criteria, 1993.

For statistical analysis we used STATA 9.0 program. Chi-square, Exact Fischer and Man-Whitney tests were used for univariate and vicariate analysis. Tstudent test was used to compare HAI rates of HIV+ and HIV-groups.

This protocol was evaluated and approved by the hospital's Ethic in Research Commission and it is in conformity with the Brazilian National Health Council Resolution 196/96.

\section{RESULTS}

During the study period, 144 cases of HAI were diagnosed in 106 patients. Sixty were HIV- and 46 HIV+. Eighty nine (62\%) HAI occurred in the HIV-group.
The most prevalent admission diagnosis in the HIV-group was Tetanus (24/60 patients-40\%), while in the HIV+ group, respiratory infection was the most frequent one (33/46-72\%). Table 1 shows the clinical, epidemiological and laboratorial characteristics of the studied patients.

The use of invasive devices, such as mechanical ventilation, central-line catheter and vesical catheter, was identified in $114 \mathrm{HAI}$. Pneumonia was the most prevalent HAI (83/144-80\%), almost all of them related to mechanical ventilation $(81 / 83-96 \%)$. Table 2 shows the distribution of HAI associated with invasive Devices Utilization (DU) in both groups.

HAI rates, per 1000 patient-days, were equivalent in both groups (31 HIV+ Vs 30, 8 HIV-; p = 0, 69). Table 3 and 4 describe HAI rates associated with DU and DU rates in each group.

Only 8 patients had the $\mathrm{CD}_{4}$ count registered on chart. Average $\mathrm{CD}_{4}$ count was 158 cels $\mathrm{mm}^{-3}$ (minmax: 9-254). Only 11 patients could be classified using the CDC HIV infection staging criteria then: 8 were $\mathrm{C} 3$ and 3 were $\mathrm{B} 1$.

Table 1: Clinical, epidemiological and laboratorial characteristics of patients admitted to St Joseph Hospital ICU ${ }^{\text {a }}$, from January 2006 to December 2007

\begin{tabular}{|c|c|c|c|}
\hline Characteristics & $\begin{array}{l}\text { HIV negative } \\
(\mathrm{n}=60)\end{array}$ & $\begin{array}{l}\text { HIV positive } \\
(\mathrm{n}=46)\end{array}$ & $\mathrm{p}$ \\
\hline Gender: $\quad$ Male $(\%)$ & $44(73.3)$ & $38(82.6)$ & 0.25 \\
\hline Female $(\%)$ & $16(26.7)$ & $8(17.4)$ & \\
\hline Age (average-years) & 51.000 & 41.0 & 0.00 \\
\hline Apache (average) & 17.600 & 18.0 & 0.87 \\
\hline ALOS $^{\mathrm{b}}$ in ICU (average-days) & 26.800 & 20.4 & 0.02 \\
\hline $\begin{array}{l}\text { Time to } 1 \text { st } \mathrm{HAI}^{\mathrm{c}} \text { diagnose } \\
\text { (Average-days) }\end{array}$ & 11.800 & 10.7 & 0.72 \\
\hline $\begin{array}{l}\text { Leukocyte count } \\
\text { (average-cels/dl) }\end{array}$ & 9.483 & 5.961 & 0.00 \\
\hline Neutrophil (average-\%) & 64.8000 & 64.9 & 0.73 \\
\hline Number of HAIs: 1 & $40(66.7)$ & $41(89.1)$ & 0.01 \\
\hline$>1$ & $20(33.3)$ & $5(10.9)$ & \\
\hline Clinical outcome: Discharge (\%) & $26(44.8)$ & $13(28.9)$ & 0.09 \\
\hline Death $(\%)$ & $32(55.2)$ & $32(71.1)$ & \\
\hline
\end{tabular}

Table 2: Distribution of HAI associated with invasive devices utilization in patients admitted to St Joseph Hospital ICU ${ }^{\text {a }}$. from January 2006 to December 2007

\begin{tabular}{lllll}
\hline HAI & $\begin{array}{l}\text { HIV negative } \\
(\mathrm{n}=60)\end{array}$ & $\begin{array}{l}\text { HIV positive } \\
(\mathrm{n}=46)\end{array}$ & $\begin{array}{l}\text { Prevalence ratio } \\
-95 \% \mathrm{CI}\end{array}$ & $\mathrm{p}$ \\
\hline $\mathrm{VAP}^{\mathrm{b}}$ & $47(58 \%)$ & $34(42 \%)$ & $0.85(0.36-2.09)$ & 0.70 \\
$\mathrm{CLAB}^{\mathrm{c}}$ & $13(62 \%)$ & $08(28 \%)$ & $0.77(0.25-2.24)$ & 0.60 \\
$\mathrm{CAUTI}^{\mathrm{d}}$ & $10(77 \%)$ & $02(23 \%)$ & $0.23(0.02-1.18)$ & 0.06 \\
\hline${ }^{\mathrm{a}} \mathrm{ICU}=$ Intensive Care & Unit; ${ }^{\mathrm{b}}$ VAP $=$ & Ventilator Associated \\
Pneumonia; ${ }^{\mathrm{c}}$ CLAB & $=$ Central-Line Associated Primary & Arimary \\
Bloodstream infection; & ${ }^{\mathrm{d}}$ CAUTI = Catheter Associated Urinary \\
Tract Infection
\end{tabular}


Table 3: HAI rates. per 1000 device-days. in patients admitted to St. Joseph Hospital ICU ${ }^{\text {a }}$ from January 2006 to December 2007 Rate $\left(\mathrm{n}^{\circ} \mathrm{HAI}{ }^{*} 1000 / \mathrm{MV}^{\mathrm{b}} . \mathrm{VC}^{\mathrm{c}}\right.$ or $\mathrm{CVC}^{\mathrm{d}}$ - days)

\begin{tabular}{lccl} 
HAI & HIV negative $(\mathrm{n}=60)$ & HIV positive $(\mathrm{n}=46)$ & $\mathrm{p}$ \\
\hline $\mathrm{VAP}^{\mathrm{b}}$ & 19.9 & 24.0 & 0.38 \\
CAUTI $^{\mathrm{c}}$ & 4.5 & 1.5 & 0.09 \\
CLBA $^{\mathrm{d}}$ & 5.6 & 5.1 & 0.74 \\
\hline
\end{tabular}

${ }^{\mathrm{a}} \mathrm{ICU}=$ Intensive Care Unit; ${ }^{\mathrm{b}} \mathrm{VAP}=$ Ventilator Associated Pneumonia; ${ }^{\mathrm{c}} \mathrm{CLAB}=$ Central-line Associated primary bloodstream infection; ${ }^{\mathrm{d}}$ CAUTI $=$ Catheter Associated Urinary Tract Infection

Table 4: Device Utilization (DU) rate in patients admitted to St Joseph Hospital ICU'. January 2006 to December 2007 DU rate ( ${ }^{\circ}$ DU-days/patient-days)

\begin{tabular}{llll} 
DU & HIV negative $(\mathrm{n}=60)$ & HIV positive $(\mathrm{n}=46)$ & $\mathrm{p}$ \\
\hline $\mathrm{VM}^{\mathrm{b}}$ & 0.80 & 0.78 & 0.41 \\
$\mathrm{VC}^{\mathrm{c}}$ & 0.70 & 0.77 & 0.69 \\
$\mathrm{CVC}^{\mathrm{d}}$ & 0.81 & 0.87 & 0.75 \\
\hline
\end{tabular}

${ }^{\mathrm{a}} \mathrm{ICU}=$ Intensive Care Unit, ${ }^{\mathrm{b}} \mathrm{VAP}=$ Mechanical Ventilation; ${ }^{\mathrm{c}} \mathrm{VC}=$ Vesical Catheter, ${ }^{\mathrm{d}} \mathrm{CVC}=$ Central Venous Catheter

\section{DISCUSSION}

ICU patients' higher risk of HAI has been well demonstrated in many studies (Weinstein, 1991; Esen and Leblebicioglu, 2004). Others show that HIV positive patients are at increased risk for HAI (Stroud $e t$ al., 1997). However our data showed no difference between HIV positive and HIV negative patients nosocomial infection rates. Indeed, HIV+ patients had a shorter ICU stay (ALOS) and a tendency to have a smaller number of HAI. Believe that the earlier evolution to death could explain it. Possibly poor immune status of HIV positive patients could be associated with the development and fewer HAI. Unfortunately, our study had an important limitation because $\mathrm{CD}_{4}$ count was registered in only 8 patients; therefore this hypothesis cannot be confirmed.

In our data HIV+ patients were younger than HIVones. This could be explained by the known tendency of HIV/AIDS to compromise young patients. Brazilian AIDS report showed that most of the notified cases in 2010 occurred in patients between 25-49 years (Brasil, 2010).

ICU patients are frequently submitted to invasive procedures for intensive monitoring which increases the risk for HAI. Our series demonstrated that invasive devices were equally frequently used in the studied groups and showed no difference when we compared the DU rates. Also, there was no significant difference between patient-days HAI rates in both groups. Padoveze et al. (2002) HAI to assess the infectious disease unit in a University Hospital in Sao Paulo, found that the use of urinary catheter and central venous catheter was significantly higher in HIV positive patients.

Some authors have showed that CLAB is the most frequent HAI in HIV+ patients (Padoveze et al., 2002; Petrosillo et al., 2002). Others found that skin and soft tissue infections are the most prevalent infection sites (Frank et al., 1997). In our study VAP was the most frequent HAI in both studied groups. The fact that the majority of HIV+ patients were admitted to the ICU with respiratory infections could explain this finding.

The transversal design and the difficulty in collecting CD4 count data from HIV+ patients' chart were the principal study limitations and made it impossible to evaluate the CD4 level impact on HAI. Nevertheless, we believe that this study was very important because it demonstrated that HAI are frequent in severely ill patients, in spite of their HIV status.

\section{CONCLUSION}

In conclusion, our data show that HAI occurs in ICU patients, independently of their HIV status. It also suggests that HAI prevention precautions should be intensively used, especially in ICU patients, in order to minimize HAI risks and serious consequences.

\section{REFERENCES}

Brasil, 2010. Ministerio da Saúde. Secretaria de Vigilância em Saúde. Boletim Epidemiológico da Aids.

Esen, S. and H. Leblebicioglu, 2004. Prevalence of Nosocomial Infections at Intensive Care Units in Turkey: A Multicentre 1-day Point Prevalence Study. Scand. J. Infect. Dis., 36: 144-148. DOI: 10.1080/00365540410019156 PMID: 15061671

Frank, U., J. Griffith, F.D. Dascchenr, G. Schulgen and J. Milss., 1997. Incidence and epidemiology of nosocomial infections in patients infected with human immunodeficiency virus. Clin. Infect. Dis., 25: 318-320. DOI: $10.1086 / 514553$ PMID: 9332532

Goetz, A.M., C. Squier, M.M. Wagener and R.R. Muder, 1994. Nowosocomial infections in the human immunodeficiency virus-infected patient: A two-year survey. Am. J. Infect. Control., 22: 334339. DOI: $10.1016 / 0196-6553(94) 90031-0$

Kubler, A., W. Duszynska, V.D. Rosenthal, M. Fleischer and T. Kaiser et al, 2011. Deviceassociated infection rates and extra length of stay in an intensive care unit of a university hospital in Wroclaw, Poland: International Nosocomial Infection Control Consortium's (INICC) findings. J. Crit. Care. PIMD: 21737244 
Machado, A., A.A.B. Ferraz, E. Ferraz, E. Arruda and J. Nobre et al., 2001. Prevençao da Infecçao Hospitalar.

Marra, A.R., L.F.A. Camargo, A.C.C. Pignatari, T. Sukiennik, P.R.P. Behar et al., 2011. Nosocomial bloodstream infections in Brazilian Hospitals: Analysis of 2,563 cases from a prospective nationwide surveillance study. J. Clin. Microbiol., 49: 1866-1871. DOI: 10.1128/JCM.00376-11

Padoveze, M.C., P. Trabasso and M.L. Branchini., 2002. Nosocomial infections among HIV-positive and HIV-negative patients in a Brazilian infectious diseases unit. Am. J. Infect. Control, 30: 346-350. DOI: 10.1067/mic.2002.125220 PMID: 12360143

Petrosillo, N., G. Pugliese, E. Giardi, F. Pallavicini and G. Carosi et al., 1999. Nosocomial infections in HIV infected patients. AIDS, 13: 599-605. DOI: 10.1097/00002030-199904010-00009 PMID: 10203385

Petrosillo, N., L. Pagani and G. Ippolito., 2003. Nosocomial infections in HIV-positive patients: An overview. Infections, 2: 28-34. PMID: 15018470

Petrosillo, N., P. Viale, E. Nicastri, C. Arici and E. Bombana et al., 2002. Nosocomial bloodstream infections among human immunodeficiency virusinfected patients: Incidence and risk factors. Clin. Infect. Dis., 34: 677-685. DOI: 10.1086/338813 PMID: 11823956
Pittet, D. and R.P. Wenzel, 1995. Nosocomial bloodstream infections. Secular trends in rates, mortality, and contribution to total hospital deaths. Arch. Intern. Med., 155: 1177-1184. PMID: 7763123

Rosenthal, V.D., D.G. Maki, S. Jamulitrat, E.A.S. Medeiros and S.K. Todi et al., 2010. International Nosocomial Infection Control Consortium (INICC) report, data summary for 2003-2008, issued June 2009. Am. J. Infect. Control, 38: 95-104. DOI: 10.1016/j.ajic.2009.12.004 PMID: 20176284

Stroud, L., P. Srivastava, D. Culver, A. Bisno and D. Rimland et al., 1997. Nosocomial infections in HIV-infected patients: Preliminary results from a multicenter surveillance system (1989-1995). Infect. Control. Hosp. Epidemiol., 18: 479-485. DOI: 10.1086/647652 PMID: 9247830

Trilla, A., 1994. Epidemiology of nosocomial infections in adult intensive care units. Intensive Care Med., 20: S1-S4. DOI: 10.1007/BF01745243 PMID: 7962982

Weinstein, R.A., 1991. Epidemiology and control of nosocomial infections in adult intensive care units. Am. J. Med, 91: 179-184. DOI: 10.1016/00029343(91)90366-6

Wenzel, R.P., 1995. The economics of nosocomial infections. J. Hosp. Infect., 31: 79-87. DOI: 10.1016/0195-6701(95)90162-0 